\title{
QUANTIFICAÇÃO DE BIOMASSA TOTAL E CARBONO ORGÂNICO EM POVOAMENTOS DE Araucaria angustifolia (BERT.) O. KUNTZEE NO SUL DO ESTADO DO PARANÁ, BRASIL
}

\author{
Total biomass and organic carbon quantification of Araucaria \\ angustifolia (BERT.) O. kuntze stands in southern Parana, Brazil
}

\author{
Luciano Farinha Watzlawick* \\ Carlos Roberto Sanquetta* \\ Júlio Eduardo Arce \\ Rafaelo Balbinot
}

\section{Resumo}

Atualmente é cada vez maior o interesse pela fixação de carbono em florestas plantadas, principalmente devido a sua elevada taxa de crescimento e conseqüente capacidade de remover o dióxido de carbono da atmosfera. Porém, fatos políticos estão tornando este assunto especialmente interessante para os países que não fazem parte do chamado Anexo I, do Protocolo de Quioto. Em função deste interesse e preocupação, o presente estudo teve por objetivo estimar a biomassa total e o carbono orgânico nos diversos componentes da planta (fuste, casca, galhos vivos, galhos mortos, ramos aciculados e na raiz) de um povoamento Araucaria angustifolia (Bert.) O. Ktze, uma das espécies florestais chave do Brasil.

Palavras-chave: Araucária, Fixação de carbono, Determinação de biomassa.

\section{Abstract}

Carbon sequestration in forest plantations has attracted interest of scientists and society in these days because their fast growth rate and capability to remove carbon dioxide from the atmosphere. However, related political facts are becoming particularly important to those countries that are not listed in the Annex I of the Kyoto Protocol. This scenario led us to carried this study, whose objective was to estimate organic carbon amount in several plant parts (bole, bark, living branches, needles and roots) of a stand of Araucaria angustifolia (Bert.) O. Ktze, which is a key tree species in Brazil.

Keywords: Araucaria, Carbon sequestration, Biomass determination.

\footnotetext{
* Prof. M. Sc., Doutorando Manejo Florestal. Universidade Federal do Paraná, Setor de Ciências Agrárias, Departamento de Silvicultura e Manejo. Av. Lothário Meisser, 3400 (Centro de Ciências Florestais e da Madeira), Jardim Botânico, Curitiba - PR, CEP 80210170.

E-mail: luciano_farinha@uol.com.br

** Prof. Dr. Inventário Florestal, e-mail: sanqueta@floresta.ufpr.br

*** Prof. Dr. Manejo Florestal, e-mail: jarce@floresta.ufpr.br

***** Mestrando em Manejo Florestal, e-mail: rbalbinot@yahoo.com.br
} 


\section{Introdução}

A araucária, Araucaria angustifolia (Bert.) O. Ktze., conforme Reitz (1979), é encontrada formando agrupamentos densos, principalmente na parte leste e central do planalto meridional do Brasil, abrangendo os Estados do Paraná, Santa Catarina e Rio Grande do Sul. Ocorre, ainda, na forma de manchas esparsas, no sul do Estado de São Paulo, e na região da Serra da Mantiqueira, estendendo-se até o sul de Minas Gerais e Rio de Janeiro. Esta espécie atravessa para a Província Argentina de Misiones, e no Paraguai, distante 60 km do Rio Paraná, existe um núcleo de pinhal, completamente cercado pela mata latifoliada da Bacia do Rio Paraná.

A araucária é a essência florestal nativa brasileira, que tem demonstrado o melhor comportamento em plantações. Contudo, quando se confronta o seu rendimento com o de outras coníferas exóticas, como as do gênero Pinus, na maioria dos casos, a araucária tem um desenvolvimento menor.

Atualmente é cada vez o maior interesse pela fixação de carbono em florestas plantadas, principalmente devido as suas elevadas taxas de crescimento e conseqüente capacidade de remover dióxido de carbono da atmosfera. Porém, fatos políticos estão tornando este assunto especialmente interessante para os países que não fazem parte do chamado Anexo I, do Protocolo de Quioto. Isto porque definições da Conferência da Partes realizada em Bonn, em 2001, (COP 6) e reafirmadas na COP 7, em Marrakesh, também em 2001, definiram que para estes países, a emissão de Certificados de Redução de Emissões (CERs), que poderão ser negociados no mercado internacional, somente poderão ser gerados a partir de atividades induzidas pelo homem, ou seja, por meio de florestamentos e reflorestamentos.

Para Schumacher e outros (2001), as florestas plantadas, geralmente com fins econômicos e comerciais, são orientadas por critérios técnicos, conforme um plano de manejo, definindo-se sua época de colheita. Porém durante sua existência, estas florestas realizam a atividade de captura e fixação de carbono na madeira e nos demais componentes.

A remoção do dióxido de carbono da atmosfera ocorre por meio da fotossíntese nos vegetais e sua liberação no processo de respiração, sen- do parte deste carbono armazenado nos diversos componentes das plantas, conforme Simpson e Botkin, citados por Schumacher et al. (2001).

Em função do exposto acima, o presente estudo teve por objetivos estimar a biomassa total e o carbono orgânico nos diversos componentes da planta (fuste, casca, galhos vivos, galhos mortos, ramos aciculados e na raiz), de um povoamento Araucaria angustifolia (Bert.) O. Kuntze, visando a dar contribuições no sentido de clarificar seu papel na fixação de carbono atmosférico.

\section{Materiais e métodos}

A área de estudo está localizada entre as coordenadas $26^{\circ} 20^{\prime} 35^{\prime \prime}$ e $26^{\circ} 26^{\prime} 13^{\prime \prime}$, e $51^{\circ} 19^{\prime} 49^{\prime \prime}$ e $51^{\circ} 25^{\prime} 29^{\prime}$ W, na Região Sul do Paraná, no município de General Carneiro - PR, Brasil, conforme se pode observar na figura 1.

O levantamento dos dados foi realizado em um povoamento de araucária com 30 anos de idade, de propriedade das Indústrias Pedro N. Pizzatto Ltda., empresa florestal de porte médio, que processa madeira e seus derivados.

Segundo Sanquetta (1998), os solos da área são orgânicos e hidromórficos, pouco profundos e férteis, com predomínio de cambissolos associados com solos litólicos, bem como outras associações com podzólicos e latossólicos, além de solos orgânicos. O clima é caracterizado como subtropical úmido mesotérmico (Cfb), pela classificação de Köppen, com verões frescos, e a temperatura média anual variando entre $15^{\circ} \mathrm{C}$ a $19^{\circ} \mathrm{C}$, nos meses mais frios a mínima pode alcançar $10^{\circ} \mathrm{C}$, enquanto nos períodos mais quentes as temperaturas podem alcançar até $36^{\circ} \mathrm{C}$.

O mesmo autor relata que a vegetação natural encontrada corresponde ao bioma da Floresta Ombrófila Mista ou Floresta com Araucária, sendo uma das poucas formações florestais brasileiras que têm sua fisionomia tão bem caracterizada pela presença de uma espécie vegetal. Acrescenta ainda que, mesmo com a profunda alteração a que foi submetida a cobertura vegetal do Paraná, a presença de remanescentes de araucária, mesmo que isolados, atesta a distribuição do bioma e facilita grandemente a sua definição. 
FIGURA 1- Localização da área de estudo

Figure 1 - Localization of the studied area

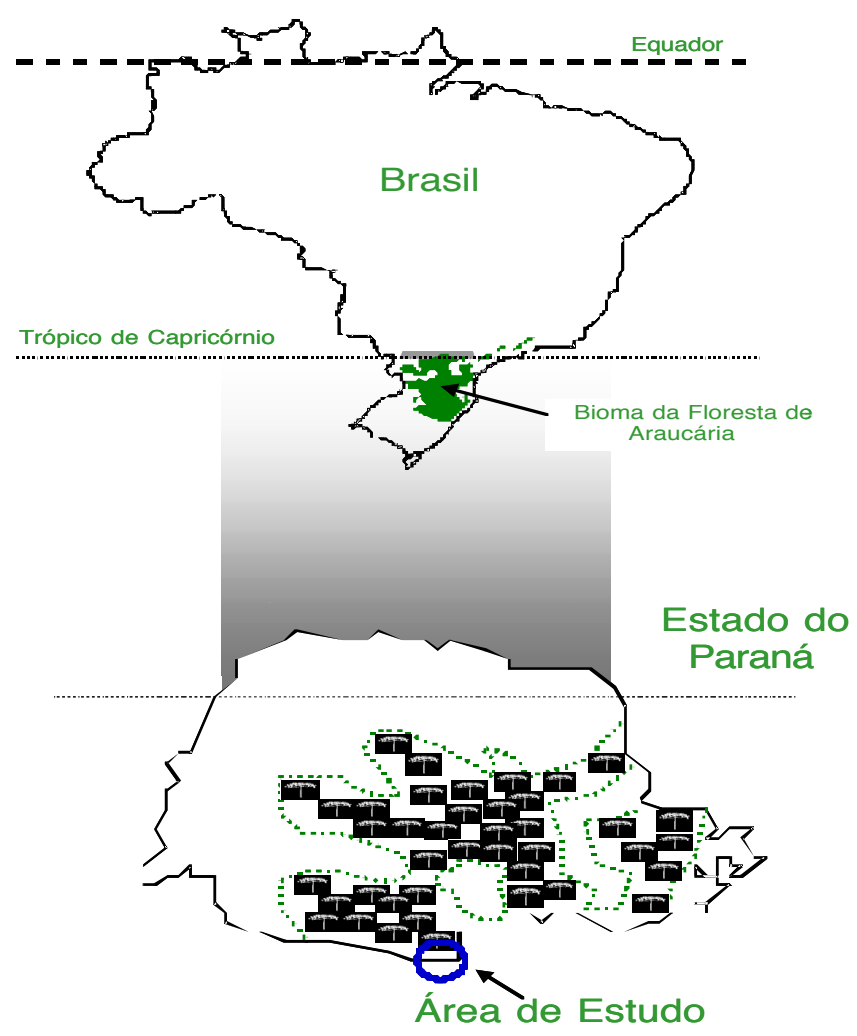

Conforme dados provenientes de inventário florestal, fornecido pela empresa, o povoamento de Araucaria angustifolia em estudo, com 30 anos de idade, possui uma densidade de 540 árvores por hectare, DAP médio de $26,7 \mathrm{~cm}$, altura total média de 18,9 m e um volume médio de 100,16 $\mathrm{m}^{3} /$ ha.

\section{Procedimentos de campo e de laboratório}

Os dados de biomassa foram coletados no campo, utilizando-se o método destrutivo de quantificação, utilizando-se para tanto a amostragem de 10 (dez) árvores, distribuídas aleatoriamente pelo povoamento. Todos os indivíduos foram derrubados para obtenção das varáveis dendrométricas DAP, altura total e altura comercial.

Depois de abater cada árvore, seus componentes eram amostrados. Estas amostras eram pesadas no campo, em balança mecânica com precisão de 0,1 g para determinação do teor de umidade.

A amostragem dos ramos aciculados (grimpas) foi feita na ponta, meio e base da copa. No caso dos galhos, adotou-se o mesmo procedimento, retirando-se amostras com casca na extremidade, meio e base dos galhos. As amostras de casca do tronco foram retiradas na base, à meia altura e na ponta da árvore, nos mesmos locais onde foram retirados os discos para amostragem da madeira. A quantificação do peso total da casca foi feita por relações de fator de casca. Já a madeira do fuste era secionada e pesada diretamente em uma balança com capacidade para 300 kg. Após a amostragem, os galhos eram removidos para coleta e pesagem dos ramos aciculados. Depois de separados, os galhos eram igualmente pesados.

A biomassa radicial foi quantificada na área determinada como área teórica de ocupação de cada planta dentro do povoamento. No caso, em se tratando de um plantio de $2,5 \mathrm{~m}$ x 2,0 m, a área útil foi de $5 \mathrm{~m}$ ", a qual era escavada até $0,5 \mathrm{~m}$ de profundidade, onde as raízes com diâmetro igual ou superior a $1 \mathrm{~cm}$ eram coletadas. Para esta amostragem de raiz foram selecionadas duas árvores, que apresentavam o diâmetro médio do povoamento.

Após a pesagem e amostragem dos diversos componentes, estes eram levados para o laboratório e secos em estufa de renovação e circulação de ar, a uma temperatura constante de $75^{\circ} \mathrm{C}$, até atingir o peso constante, para posterior determinação de peso seco e preparação para análise química do teor de carbono orgânico.

As análises de carbono orgânico no tecido vegetal foram executadas de acordo com a metodologia proposta por Tedesco e outros (1995), realizadas no Laboratório de Ecologia Florestal da Universidade Federal de Santa Maria, Estado do Rio Grande do Sul, Brasil.

\section{Resultados e discussões}

Considerando a biomassa total para a Araucaria angustifolia, conforme pode ser observado na Tabela 1 , verifica-se que a parte aérea possui $84,61 \%$ da biomassa verde total das árvores, estando subdividida na seguinte proporção: madeira (42,50\%), casca $(22,68 \%)$, ramo aciculado (7,63\%), galho vivo $(11,33 \%)$ e galho morto $(0,77 \%)$, restando 15,09\% para a biomassa subterrânea (raízes). 
Já no que concerne à biomassa seca, obteve-se os seguintes percentuais: madeira (42,50\%), casca $(23,80 \%)$, ramo aciculado $(7,64 \%)$, galho vivo (11,64\%) e galho morto (1,18\%), restando $15,75 \%$ para a biomassa subterrânea (raízes).

No que diz respeito aos quantitativos de carbono fixados, os percentuais encontrados, neste estudo, foram: madeira (41,11\%), casca $(21,84 \%)$, ramo aciculado (6,93\%), galho vivo $(11,14 \%)$ e galho morto (1,13\%), restando $17,62 \%$ para a biomassa subterrânea (raízes).

Os teores de carbono no povoamento de araucária, em termos percentuais, variaram de $40,0 \%$ para o componente casca a $48,8 \%$ para a raiz. Para a madeira, este percentual foi de $44,1 \%$, um tanto superior ao percentual dos ramos aciculados e superior aos percentuais contidos nos galhos.

TABELA 1 - Valores de biomassa total verde, seca e carbono orgânico em povoamento de Araucaria angustifolia aos 30 anos de idade no Estado do Paraná, Brasil

Table 1 - Values of green total biomass, dry and organic carbon of Araucaria angustifolia stands with 30 years of age in the State of the Parana, Brazil

\begin{tabular}{lcccc}
\hline Componente & $\begin{array}{c}\text { Biomassa } \\
\text { Verde }\left(\mathbf{M g ~ h a}^{-1}\right)\end{array}$ & $\begin{array}{c}\text { Biomassa Seca } \\
\left(\mathbf{M g ~ h a}^{-1}\right)\end{array}$ & $\begin{array}{c}\text { Carbono Orgânico } \\
\left(\mathbf{M g ~ h a}^{-1}\right)\end{array}$ & $\begin{array}{c}\text { \% da } \\
\text { Massa seca }\end{array}$ \\
\hline Madeira & 310,6 & 123,9 & 54,6 & 44,1 \\
Casca & 165,7 & 72,4 & 29,0 & 40,0 \\
Ramo aciculado & 55,8 & 20,9 & 9,2 & 44,0 \\
Galho vivo & 82,8 & 35,4 & 14,8 & 41,8 \\
Galho morto & 5,6 & 3,6 & 1,5 & 41,7 \\
Raiz & 110,3 & 47,9 & 23,4 & 48,8 \\
TOTAL & $\mathbf{7 3 0 , 8}$ & $\mathbf{3 0 4 , 2}$ & $\mathbf{1 3 2 , 8}$ & $\mathbf{4 3 , 6}$ \\
\hline
\end{tabular}

Estudando um povoamento florestal de Pinus taeda, com 20 anos de idade, Balbinot et al. (2000) estimaram a biomassa seca dos componentes acículas, galhos, casca, madeira e raízes em 8,$1 ; 47,7 ; 10,9 ; 203,3$ e $37,1 \mathrm{Mg} \mathrm{ha}^{-1}$, respectivamente. Já o carbono acumulado, nestes componentes, foi de 3,5; 17,6; 4,1; 90,4; e 17,5, respectivamente para as acículas, galhos, casca, madeira e raízes. Estes dados, referem-se a uma média de 300 árvores por hectare, portanto, comparativamente a floresta de Pinus taeda, aos vinte anos de idade, sob este ponto de vista, apresentou-se mais produtiva, com uma massa seca de $307,1 \mathrm{Mg} \mathrm{ha}^{-1}$, representando $133,1 \mathrm{Mg} \mathrm{ha}^{-1}$. Como visto acima, a floresta de Araucaria angustifolia atinge valores quase iguais a estes somente aos trinta anos de idade e com uma densidade de 540 árvores por hectare, isto é, 304,2 $\mathrm{Mg} \mathrm{ha}^{-1}$ de biomassa seca, que corresponde a uma fixação de carbono de 132,8 $\mathrm{Mg} \mathrm{ha}^{-1}$, considerando inclusive os galhos secos, o que não foi o caso do estudo com Pinus taeda.

Schumacher et al., (2001), trabalhando com povoamentos de Acacia mearnsii, com 6 anos de idade, encontraram os seguintes valores para os mesmos componentes: 7,6; 3,3; 16,2; 7,8; 90,9 e 12,7 $\mathrm{Mg} \mathrm{ha}^{-1}$ e valores de carbono orgânico, 3,4; 1,4; 6,3;3,0;36,6 e 5.0, $\mathrm{Mg} \mathrm{ha}^{-1}$, respectivamente para os componentes folhas, galhos mortos, galhos vivos, casca, madeira e as raízes. Somando-se estes valores, obteve-se um total de 138,5 $\mathrm{Mg} \mathrm{ha}^{-1}$ de biomassa seca e 55,7 $\mathrm{Mg} \mathrm{ha}^{-1}$ de carbono fixado, considerando um espaçamento de $3 \times 1,3$ metros, ou seja, aproximadamente 2.565 árvores por hectare. Nota-se, assim, diferenças relevantes com os resultados do presente estudo.

Rochadelli (2001), estudando a estrutu- 
ra atômica de fixação de carbono em reflorestamentos de Mimosa scabrella (Bracatinga), em idades de 1 a 7 anos de idade, concluiu que a espécie apresenta uma concentração de carbono que varia entre 40 a $45 \%$ da biomassa total de madeira com casca, valores estes que são semelhantes aos encontrados por este trabalho.

No caso deste trabalho, a quantidade de carbono fixado pelas raízes representou 17,6\% do total de carbono fixado pelo povoamento, sendo que para Balbinot et al. (2000) e Schumacher et al. (2001) este componente representou $13,1 \%$ e $8,9 \%$ do total de carbono fixado, respectivamente, demonstrando diferenças bastante expressivas entre os três estudos.

Os fatos acima mostram a variabilidade da magnitude destas variáveis, dados que são muito influenciados pela espécie, pela densidade, pelo sítio e também pelas práticas de manejo. Portanto, é importante se ter muita cautela ao fazer qualquer extrapolação de resultados, sendo sempre importante se obter estimativas fidedignas no tocante à biomassa ao conteúdo de carbono em plantios florestais.

Adicionalmente, é importante ressaltar que os quantitativos de biomassa da raiz variam muito, com a espécie e o espaçamento, conforme observam Reis et al., (1993). Segundo os autores, a deficiência desta informação dificulta a determinação precisa do balanço do carbono em um ecossistema florestal. Desta forma, é imprescindível que mais estudos sejam feitos no sentido de elucidar a porção representada pela biomassa e pelo carbono, fixado pelos diferentes tipos de floresta.

\section{Conclusões}

- Do total da biomassa seca em um povoamento de Araucaria angustifólia, aos 30 anos de idade, 40,73\% correspondem à porção do fuste sem casca, 23,80\% à porção casca, 19,69\% a galhos e ramos e $15,75 \%$ à raiz;

- Do total de carbono, fixado pela floresta, $41,1 \%$ representam o componente madeira do fuste sem casca, 21,84\% à porção casca, $19,20 \%$ a galhos e ramos e $17,62 \%$ à raiz;

- Os teores de carbono no povoamen- to de araucária, em termos percentuais, variaram razoavelmente, de 40,0\% para o componente casca a $48,8 \%$ para a raiz, demonstrando que é preciso ter cuidados ao utilizar valores desses teores de forma indiscriminada;

- A literatura brasileira demonstra que existem muitas variações em termos de biomassa, em diferentes plantios sujeitos a diferentes condições de desenvolvimento. Porém, os teores de carbono, apesar de apresentarem algumas variações, são bem mais estáveis, oscilando entre 40 a 50\%, com média em torno de $45 \%$ da biomassa seca.

\section{Referências}

BALBINOT, R.; SCHUMACHER, M.V.; HERNANDES, J.I. Carbono orgânico em uma floresta de Pinus taeda na Região de Cambará do Sul - RS. In: CONGRESSO E EXPOSIÇÃO INTERNACIONAL SOBRE FLORESTAS, 6., 2000, Porto Seguro. Anais... Porto Seguro - BA, 2000. p.56.

REIS, M. das G. F.; REIS dos G. G.; VALENTE, O. F.; FERNANDES, H. A. de C. Seqüestro e armazenamento de carbono em florestas nativas e plantadas dos estados de Minas gerais e Espírito Santo. In: EMISSÃO x seqüestro de $\mathrm{CO}_{2}$ : uma nova oportunidade de negócios para o Brasi, 1994. Rio de Janeiro. Anais... Rio de Janeiro, p. 155-195, 1994.

REITZ, R.; KLEIN, R. M.; REIS, A. Madeiras do Brasil. Florianópolis : Lunardelli, 1979. 320 p.

ROCHADELLI, R. A estrutura de fixação dos átomos de carbono em reflorestamentos (Estudo de caso: Mimosa scabrelldentham, bracatinga). Curitiba, 2001. 86f. Tese. (Doutorado em Ciências Florestais ) - Universidade Federal do Paraná, 2001.

SANQUETTA, C. R. Inventário Contínuo em Floresta Natural: implantação de um sistema de monitoramento de crescimento e produção. Indústrias Pedro N. Pizzatto/FUPEF, 1998. (Relatório de Pesquisa).

SCHUMACHER, M. V.; VOGEL, H. L. M.; BARICHELLO, L. R.; CALDEIRA, M. V. W. Quantificação do carbono orgânico em floresta de 
Acacia mearnsii De Wild em diferentes idades. In: SIMPÓSIO LATINO-AMERICANO SOBRE MANEJO FLORESTAL, 2., 2001. Anais... Santa Maria, RS, p.387-399, 2001.

TEDESCO, M. J.; VOLKWEISS, S. J.; BOHNEN, H. Análise de solos, plantas e outros materiais.
Porto Alegre: UFRGS, Departamento de Solos/ Faculdade de Agronomia, 1995. 174p. (Boletim Técnico, 5).

Recebido 3/4/2002

Aprovado 20/3/2003 